\title{
Article \\ Characterization of miRNAs in Embryonic, Larval, and Adult Lumpfish Provides a Reference miRNAome for Cyclopterus lumpus
}

\author{
Setu Chakraborty $^{1}$, Nardos T. Woldemariam ${ }^{2}$, Tina Visnovska ${ }^{3}{ }^{\mathbb{D}}$, Matthew L. Rise ${ }^{4}$, Danny Boyce ${ }^{5}$, \\ Javier Santander $1, * \mathbb{D}$ and Rune Andreassen $2, * \mathbb{D}$
}

check for updates

Citation: Chakraborty, S.;

Woldemariam, N.T.; Visnovska, T.; Rise, M.L.; Boyce, D.; Santander, J.; Andreassen, R. Characterization of miRNAs in Embryonic, Larval, and Adult Lumpfish Provides a Reference miRNAome for Cyclopterus lumpus. Biology 2022, 11, 130. https:// doi.org/10.3390/biology11010130

Academic Editor: Patricia Pereiro

Received: 23 November 2021

Accepted: 7 January 2022

Published: 13 January 2022

Publisher's Note: MDPI stays neutral with regard to jurisdictional claims in published maps and institutional affiliations.

Copyright: (C) 2022 by the authors. Licensee MDPI, Basel, Switzerland. This article is an open access article distributed under the terms and conditions of the Creative Commons Attribution (CC BY) license (https:// creativecommons.org/licenses/by/ $4.0 /)$.
1 Marine Microbial Pathogenesis and Vaccinology Laboratory, Department of Ocean Sciences, Memorial University of Newfoundland, 0 Marine Lab Rd, St. John's, NL A1C 5S7, Canada; schakraborty@mun.ca

2 Department of Life Sciences and Health, Faculty of Health Sciences, OsloMet-Oslo Metropolitan University, Pilestredet 50, N-0130 Oslo, Norway; nardostwoldemariam@gmail.com

3 Bioinformatics Core Facility, Oslo University Hospital, 0372 Oslo, Norway; tina.visnovska@rr-research.no

4 Department of Ocean Sciences, Faculty of Sciences, Memorial University of Newfoundland, 0 Marine Lab Rd, St. John's, NL A1C 5S7, Canada; mrise@mun.ca

5 Dr. Joe Brown Aquatic Research Building (JBARB), Department of Ocean Sciences, Memorial University of Newfoundland, 0 Marine Lab Rd, St. John's, NL A1C 5S7, Canada; dboyce@mun.ca

* Correspondence: jsantander@mun.ca (J.S.); rune.andreassen@oslomet.no (R.A.)

Simple Summary: Lumpfish (Cyclopterus lumpus) is an emergent aquaculture species, and its miRNA repertoire is still unknown. miRNAs are critical post-transcriptional modulators of teleost gene expression. Therefore, a lumpfish reference miRNAome was characterized by small RNA sequencing and miRDeep analysis of samples from different organs and developmental stages. The resulting miRNAome, an essential reference for future expression analyses, consists of 443 unique mature miRNAs from 391 conserved and eight novel miRNA genes. Enrichment of specific miRNAs in particular organs and developmental stages indicates that some conserved lumpfish miRNAs regulate organ and developmental stage-specific functions reported in other teleosts.

Abstract: MicroRNAs (miRNAs) are endogenous small RNA molecules involved in the posttranscriptional regulation of protein expression by binding to the mRNA of target genes. They are key regulators in teleost development, maintenance of tissue-specific functions, and immune responses. Lumpfish (Cyclopterus lumpus) is becoming an emergent aquaculture species as it has been utilized as a cleaner fish to biocontrol sea lice (e.g., Lepeophtheirus salmonis) infestation in the Atlantic Salmon (Salmo salar) aquaculture. The lumpfish miRNAs repertoire is unknown. This study identified and characterized miRNA encoding genes in lumpfish from three developmental stages (adult, embryos, and larvae). A total of 16 samples from six different adult lumpfish organs (spleen, liver, head kidney, brain, muscle, and gill), embryos, and larvae were individually small RNA sequenced. Altogether, 391 conserved miRNA precursor sequences (discovered in the majority of teleost fish species reported in miRbase), eight novel miRNA precursor sequences (so far only discovered in lumpfish), and 443 unique mature miRNAs were identified. Transcriptomics analysis suggested organ-specific and age-specific expression of miRNAs (e.g., miR-122-1-5p specific of the liver). Most of the miRNAs found in lumpfish are conserved in teleost and higher vertebrates, suggesting an essential and common role across teleost and higher vertebrates. This study is the first miRNA characterization of lumpfish that provides the reference miRNAome for future functional studies.

Keywords: conserved miRNA; high-throughput sequencing; lumpfish; novel miRNA; RT-qPCR 


\section{Introduction}

The discovery of microRNAs (miRNAs) in 1993 in Caenorhabditis elegans and further identification in humans and many other animals significantly alters the longstanding dogmas that defined gene regulation [1]. These studies revealed that miRNAs were a class of small noncoding RNAs that function as guide molecules in RNA silencing machinery, often termed the RNA-induced silencing complex (RISC). RISC regulates gene expression at the messenger RNA level either by degrading mRNAs targeted by the miRNAs or preventing their translation [1-3]. miRNA constitute a large family of post-transcriptional regulators with $\sim 22$ nucleotides in length and present in animals, plants, and some viruses [3,4]. Functional studies indicate that miRNAs have diverse expression patterns and regulate almost every cellular process, including developmental, physiological, and pathophysiological processes $[3,5,6]$.

miRNA biogenesis involves multiple steps; first, miRNAs are processed from primary molecules (pri-miRNAs), which are transcribed by RNA-specific endoribonuclease (Drosha) and processed into an 70 -nucleotide pre-miRNA in the nucleus [2,3,6-9]. Pre-miRNAs are then transported to the cytoplasm for further processing by the enzyme Dicer to an 22-bp miRNA/miRNA duplex [2,3,6-9]. The miRNA duplex is loaded into the RISC. Only one of the mature miRNAs (guide miRNA) is incorporated in RISC, and the other is degraded (passenger miRNA). The guide miRNA directs the RISC to target mRNAs, where the mature miRNA usually binds in the $3^{\prime}$ untranslated region (UTR) of the target mRNAs [2,3,6-9].

Teleosts are an essential component of aquatic ecosystems and a primary source of proteins for human and animal consumption worldwide. Teleosts are one of the most diverse vertebrates on the earth [10]. The exploration of the role of miRNA in teleost development, organogenesis, tissue differentiation, growth, regeneration, reproduction, endocrine system, and responses to environmental stimuli, as well as their role in the maturation of the immune system and response to infectious diseases, is still under investigation [11-17]. miRNA characterization is the first step in any investigation of their regulatory roles. Such characterizations have been carried out in some economically important fish species such as Atlantic salmon (Salmo salar), Atlantic cod (Gadus morhua), rainbow trout (Oncorhynchus mykiss), Atlantic halibut (Hippoglossus hippoglossus), channel catfish (Ictalurus punctatus), turbot (Scophthalmus maximus), Asian seabass (Lates calcarifer), olive flounder (Paralichthys olivaceus) [18-26], and fish models like zebrafish (Danio rerio) and three-spined stickleback (Gasterosteus aculeatus) [27,28].

Global production of farmed Atlantic salmon is estimated at just over 2.6 million tonnes in 2019. This growth was mainly driven by Norway and Chile, the two leading producing countries. The Norwegian salmon industry alone earned some NOK 19-20 billion (USD 2.1-2.2 billion) in profits before tax in 2019 (The Food and Agriculture Organization of United Nations (FAO), 2021) (https: / / www.fao.org/in-action/globefish/market-reports / resource-detail/en/c/1268636/) (Last accesed: 21 January 2021). Farmed salmon is the main species of the Atlantic Canadian aquaculture industry, which represents approximately $80 \%$ of Atlantic Canada's total aquaculture value [29].

Infectious diseases are a challenge for the aquaculture industry. Globally losses due to diseases in the aquaculture industry exceed US\$6 billion annually [30,31]. One of the most prominent disease challenges currently restraining Atlantic salmon aquaculture is the infestation by the parasite sea lice, specifically Lepeophtheirus salmonis and Caligus spp. [32-36]. Sea lice are a group of visible host-dependent ectoparasite copepods with vast reproductive potential [32-36]. The attached sea lice feed on salmon mucus, blood, and skin, which leads to significant physical damage and immunosuppression [32,36-39]. In addition, these effects on fish health lead to substantial economic impacts due to production losses and treatment costs $[32,37,40]$. The salmon industry in the North Atlantic region has adopted cleaner fish, e.g., Lumpfish (Cyclopterus lumpus), for biological control of sea-lice infestations [32,41-44]. However, several aspects of lumpfish biology remain unknown, including their miRNA repertoire. 
This study aimed to identify and characterize miRNA encoding genes in lumpfish by small RNAs high-throughput sequencing (HTS) followed by miRDeep2 analysis. The identification was carried out in two early developmental stages, embryos and larvae, and six organs of adult lumpfish-brain, muscle, gill, liver, spleen, and head kidney. A combination of HTS and computational analytical approaches (e.g., miRNA precursor prediction) has been successfully used for miRNA characterization in particular two early developmental stages and adult lumpfish organs. Therefore, here we provide the first reference miRNAome for lumpfish.

\section{Materials and Methods}

\subsection{Fish Holding}

Five adult lumpfish $(1100 \mathrm{~g} \pm 99.5$, male $=4$, female $=1)$ were obtained from the Joe Brown Aquatic Research Building (JBARB) at the Department of Ocean Sciences (DOS), Memorial University of Newfoundland (MUN), Canada. The animals were kept in a 23,000 L tank, with flow-through $\left(140 \mathrm{~L} \mathrm{~min}^{-1}\right)$ of UV-treated seawater $\left(6^{\circ} \mathrm{C}\right)$, ambient photoperiod (winter-spring), and 95-110\% air saturation. Biomass density was maintained at $20 \mathrm{~kg} \mathrm{~m}^{-3}$. The fish were fed daily using a commercial diet (Skretting-Europa 18 (6.0-9.0 mm pellet), Vancouver, BC, Canada) with a ratio of $0.25 \%$ of their body weight per day. Additionally, lumpfish embryos (300 degree days) and lumpfish larvae (one week posthatch) were obtained from the JBARB. Lumpfish egg masses were fertilized and maintained with flow-through in $5 \mathrm{~L}$ upwelling black nontranslucent incubators at $8-10{ }^{\circ} \mathrm{C}$ supplied with $95-110 \%$ air saturated and $5 \mu \mathrm{m}$ UV-treated filtered flow-through seawater (spring-summer) [45]. After completing the development of the embryo, the larvae hatch are maintained at $10^{\circ} \mathrm{C}$ [46].

\subsection{Ethics Statement}

The fish dissection and tissue sample collection were performed following the Canadian Council on Animal Care guidelines (https: / / ccac.ca/en/standards/guidelines/) (Last accessed: 10 January 2022) and approved by Memorial University of Newfoundland's Institutional Animal Care Committee (https:/ / www.mun.ca/research/about/acs/) (Last accessed: 10 January 2022) under the protocols \#18-1-JS and \#18-03-JS.

\subsection{Sample Collection}

Fish were euthanized with $400 \mathrm{mg}$ of MS222 (Syndel Laboratories, Vancouver, BC, Canada) per litre of seawater and dissected immediately after death confirmation. Tissue samples were collected from adult lumpfish brain, gill, skeletal muscle, liver, spleen, and head kidney. Tissue samples from five adult lumpfish, two pools of lumpfish embryos, and two pools of lumpfish larvae were immediately flash-frozen in liquid nitrogen (Air Liquide Canada Atlantic, St. John's, NL, Canada) and stored at $-80^{\circ} \mathrm{C}$ until further processing.

\subsection{RNA Extraction}

Total RNA was extracted using the mirVana RNA isolation kit (Invitrogen, Carlsbad, CA, USA) following the manufacturer's protocol. RNA concentration and integrity were quantified using spectrophotometry (Genova-nano, Jenway, Stone, Staffordshire, England) and $1 \%$ agarose gel electrophoresis. The total RNA concentrations of 32 samples (four adult individuals with brain and muscle samples, five adult individuals with gill, liver, spleen, and head kidney samples, and four samples from two early life stages) ranged from 100-3250 ng $\mu \mathrm{L}^{-1}$ (total volume $100 \mu \mathrm{L}$ ) (Table S1). Sixteen samples from two adult lumpfish, two embryos, and two larvae were used for high-throughput sequencing (HTS) by independent library preparation and sequencing of each sample (Table S2), whereas all the 32 samples were used for qPCR analysis. 


\subsection{High-Throughput Sequencing (HTS)}

The library construction and small RNA sequencing were performed by the Genomics Core Facility Oslo (Oslo University Hospital, Oslo, Norway). The NEBNext Small RNA Library Prep Set for Illumina (New England Biolabs, Inc., Ipswich, MA, USA) was used to prepare the libraries according to the manufacturer's protocol. One $\mu \mathrm{g}$ of total RNA from each sample was used as input to prepare the libraries, and a final size selection of 140-150 bp fragments using $6 \%$ polyacrylamide gel was used to enrich small RNAs. The adapter sequences ( $5^{\prime}$ AGATCGGAAGAGCACACGTCTGAACTCCAGTCAC $3^{\prime}$ ) were used in the library preparation process. Following library preparation, next-generation RNA sequencing was carried out using the Illumina Genome Analyzer IIx sequencing platform described in Woldemariam et al. [19], generating single-end reads of length $75 \mathrm{bp}$.

\subsection{Analysis of Sequencing Data}

The sequencing of raw and processed data quality was checked before miRNA discovery analysis. FastQC v0.11.9 (http:/ / www.bioinformatics.babraham.ac.uk/projects/ fastqc/) (Last accessed: 20 November 2021) was used to check the quality of both the raw sequencing data and the data obtained after adapter removal and size filtering. The adapter removal and size filtering were carried out using cutadapt v1.8.3 [47]. Reads shorter than $18 \mathrm{bp}$ and longer than $25 \mathrm{bp}$ after the adapter removal were discarded. The reads passing the filtering step were converted to fasta format with fastq_to_fasta from FASTX toolkit v0.0.14 (http:/ /hannonlab.cshl.edu/fastx_toolkit/) (Last accessed: 20 November 2021).

Each of the 16 samples were analyzed independently to detect miRNAs highly expressed in particular adult organs/tissues and early developmental stages. The lumpfish reference genome [48] and bowtie v1.0.0 [49] were used for mapping the reads to the reference genome. The workflow applied to identify novel lumpfish miRNA sequences is illustrated in Figure 1.

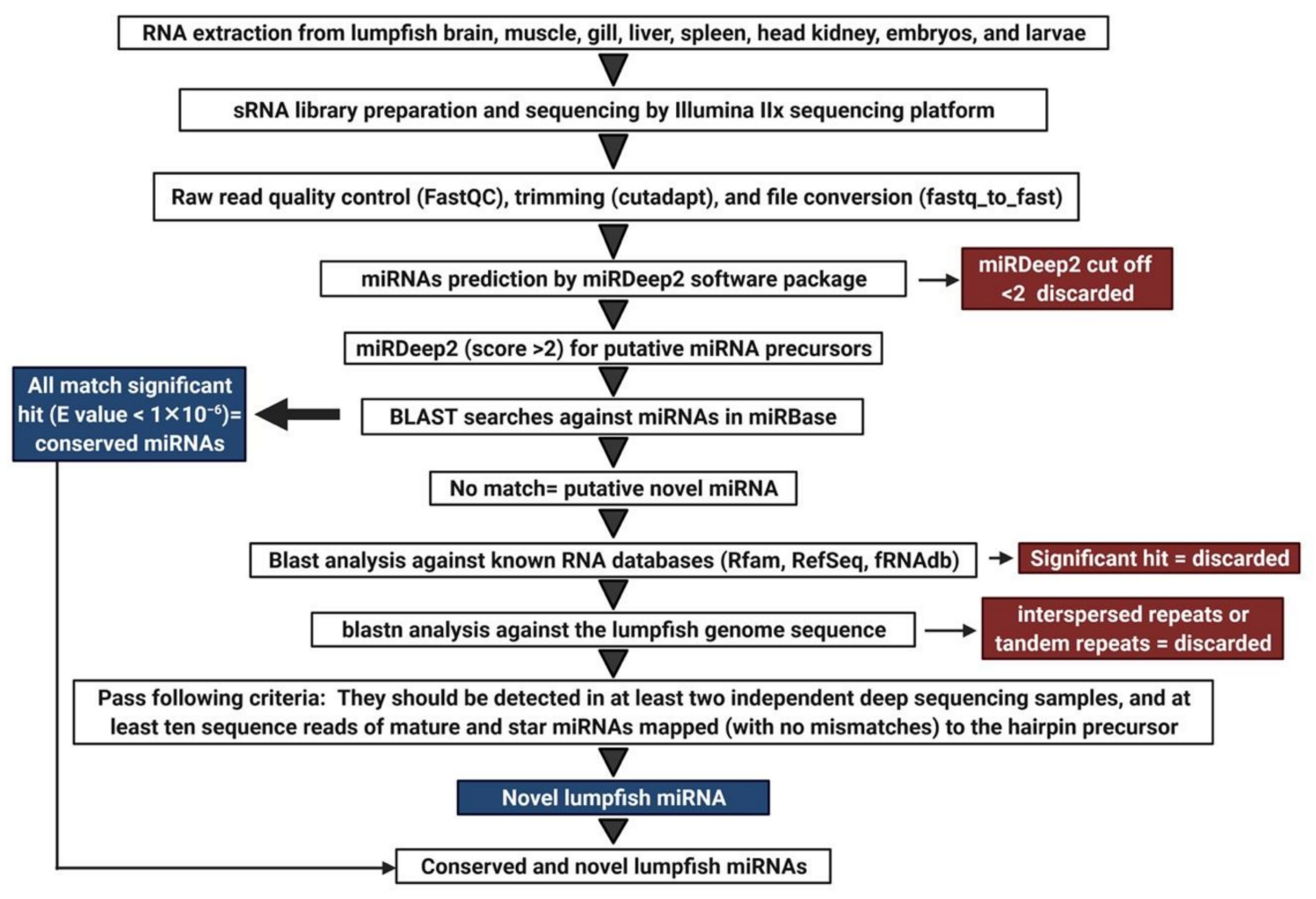

Figure 1. Experimental workflow used for characterization of lumpfish miRNAome.

High-quality trimmed reads were used to discover lumpfish miRNA using the miRDeep2 software package v0.0.7 (mapper and miRDeep2 analysis modules) applying default 
commands [50,51]. The miRDeep2 tools assign a log-odds score (the miRDeep2 score) based on an algorithm that integrates the statistics of the read positions, the frequencies of reads within hairpins, and the posterior probability that the hairpin was derived from a true miRNA gene [50]. A miRDeep2 score of $\geq 2$ was used as a cutoff to prevent false positive detection of miRNA precursors. In addition, they were inspected regarding the following criteria: (i) reads between $5^{\prime}$ and $3^{\prime}$ end of a precursor should be aligned perfectly in a discrete manner; (ii) miRNA precursors should be detected in at least two independent deep sequencing samples, and (iii) at least ten sequence reads of mature and miRNAs mapped to the hairpin precursor [52]. We further analyzed these putative precursor sequences by BLAST searches against known precursor sequences deposited in miRBase, (http:/ / www.mirbase.org/index.shtml) (last accessed on 22 November 2021). Any putative miRNA precursor sequence having a significant hit (E-value $<1 \times 10^{-6}$ ) in the BLAST analyses was regarded as a true evolutionarily conserved lumpfish ortholog of the miRNA gene in miRBase that retrieved the best hit and annotated as the evolutionarily conserved lumpfish ortholog of the miRNA gene according to the miRbase nomenclature guidelines (clu-prefix and same number as in other teleosts) [53,54]. The putative miRNA precursor sequences that were identified by miRDeep 2 and passed the additional criteria but did not show any significant match to the existing precursors in miRBase were considered putative novel miRNAs. All those sequences were further analyzed by blastn searches against RNA databases in GenBank (http:/ /blast.ncbi.nlm.nih.gov / Blast) (Last accessed: 20 November 2021), the small RNA databases Rfam (https:/ /rfam.xfam.org/ search) (Last accessed: 20 November 2021), and the functional RNA database fRNAdb (https:/ / dbarchive.biosciencedbc.jp/en/frnadb/desc.html) (Last accessed: 20 November 2021). Sequences that had a significant hit against these databases were considered other kinds of small RNA and discarded from the analysis. The remaining precursors were used as queries in blastn analysis against the lumpfish genome sequence. Sequences with a significant BLAST hit $\left(E\right.$ value $\left.<1 \times 10^{-6}\right)$ against multiple loci $(>10)$ in the lumpfish genome reference sequence were considered to be interspersed repeats or tandem repeats and discarded from the analysis. Sequences that passed all these filtering steps were regarded as true novel lumpfish miRNAs. A reference miRNAome of unique mature miRNA sequences ( $5 p$ or $3 p$ ) for expression analysis of HTS data were generated by aligning all mature miRNAs using Sequencher software 5.3 (Gene Codes Corporation, Ann Arbor, MI, USA). The identical mature miRNAs from the same families were aligned applying strict settings, and the final reference, thus, consisted of only the unique, different mature miRNAs.

\subsection{Disclosing Putative Differentially Expressed and Organ and Developmental Stage Enriched miRNAs}

The HTS data from 16 tissue samples were used to estimate the expression of individual miRNAs across the different organs and developmental stages. The adapters were trimmed from the raw reads, and the resulting reads were filtered based on size. The filtered reads from all 16 samples were mapped to the reference applying STAR aligner software (v.2.5.2b) [47]. The index for mapping was generated from the unique mature lumpfish miRNAs (see 2.6) with parameters genomeSAindexNbases 6. STAR aligner software (v.2.5.2b) with alignIntronMax1 and default parameters was then used for the mapping. Next, the output files of STAR mapping (BAM format) were processed further in R-Studio by using the feature Counts function from the Rsubread package (v.1.34.2) to produce count matrices [47]. The count tables were used as input in the DESeq2 $\mathrm{R}$ package (v.1.24.0) for differential expression analysis. Samples from an organ or developmental stage $(n=2)$ were compared to all other tissues sampled $(n=14)$. Putative differentially expressed miRNAs were defined as those with Benjamini-Hochberg adjusted $p \leq 0.05$, $\log _{2}$ fold change threshold value of at least $\leq-3.0$ or $\geq 3.0$. The miRNA abundance of the different miRNAs within a particular organ or developmental stage was estimated as the percentage of a specific miRNA out of the total based on the average of normalized read 
counts from duplicated samples (reads less than 20 were filtered out). Enriched miRNAs were analyzed for each organ and developmental stage.

\subsection{RT-qPCR}

We selected eight different miRNAs that were suggested as differentially expressed in literature and enriched in one of the organs by the DESeq2 analysis for further expression analysis with qPCR. These miRNAs had previously shown similar organ-specific enrichment in other teleosts $[19,20]$. The RNA-seq read numbers of these eight miRNAs are provided in Table S8. Those eight miRNAs (clu-miR-135c-5p, clu-miR-9b-3p, clu-miR-133ab3p, clu-miR-205-1-5b, clu-miR-203-3p, clu-miR-203a-5p, clu-miR-192a-5p, clu-miR-122-1-5p) were analysed by RT-qPCR to verify the DESeq2 results. All forward primer sequences used for $\mathrm{qPCR}$ were retrieved from the mature sequences of these miRNAs in the characterization step (methods 2.6). The primer sequences are listed in Table 1. The cDNA synthesis and qPCR were carried out applying the miScript (miScript II RT Kit and miScript SYBR Green PCR Kit) assays following the manufacturer's instructions (Qiagen, Hilden, Germany). The qPCR reaction mixture contained $12.5 \mu \mathrm{L} 2 \times$ QuantiTect SYBR Green Master Mix, $2.5 \mu \mathrm{L} 10 \times$ miScript Universal Primer, $2.5 \mu \mathrm{L}$ of $10 \mu \mathrm{M}$ forward miRNA-specific primer, $5 \mu \mathrm{L}$ RNase free water, and $2.5 \mu \mathrm{L}$ cDNA. The qPCR analysis was carried out by Mx3000p (Stratagene, Agilent Technologies, LA Jolla, CA, USA) using the following cycle, $95^{\circ} \mathrm{C}$ for $15 \mathrm{~min}$ followed by 40 cycles of $94{ }^{\circ} \mathrm{C}$ for $15 \mathrm{~s}, 55^{\circ} \mathrm{C}$ for $30 \mathrm{~s}$ and $70{ }^{\circ} \mathrm{C}$ for $30 \mathrm{~s}$ as described in Andreassen et al., 2016 [20]. The mature sequences of clu-mir-25-3p and clu-mir-17-5p were used as reference genes [20,55]. The instrument-provided ct values were applied to the LinRegPCR (v2021.1) software to calculate efficiency in all assays, and then the efficiency-adjusted Ct-values were provided [56]. The efficiency adjusted values were also used in the normalization (geomean from the two reference genes) to provide the $\mathrm{dCt}$-values. The relative change in expression in each miRNA's target organ was calculated using the comparative $\mathrm{Ct}$ method ( $\Delta \Delta \mathrm{Ct}$-method) [57]. All the comparisons were relative to the lowest expressed organ/tissue for the particular miRNA. All relative quantity (RQ) data are presented as mean \pm standard error (SE). The RQ values for each target gene were subjected to a one-way ANOVA with Tukey post-tests to compare gene expression across tissues. All statistical tests were performed using GraphPad Prism 7.04 (San Diego, CA, USA) with the $p$-value threshold set at $\leq 0.05$. The number of organ samples was four or five for each group, while the early developmental stages had two biological replicates in each group (Table S1).

Table 1. Primers used in qPCR analysis of mature miRNAs.

\begin{tabular}{cc}
\hline miRNAs & Primer ${\text { Sequences } \mathbf{( 5}^{\prime} \text { to } \mathbf{3}^{\prime} \mathbf{)}}^{\text {clu-miR-25-3p }}$ clu-miR-17-1-5p \\
clu-miR-122-1-5p & CATTGCACTTGTCTCGGTCTGA \\
clu-miR-133ab-3p & CAAAGTGCTTACAGTGCAGGTA \\
clu-miR-205-1-5p & TGGAGTGTGACAATGGTGTTTG \\
clu-miR-135c-5p & TTTGGTCCCCTTCAACCAGCTGT \\
clu-miR-203-3p & TCCTTCATTCCACCGGAGTCTG \\
clu-miR-203a-5p & TATGGCTTTTTATTCCTATGTG \\
clu-miR-192a-5p & GTGAAATGTTTAGGACCACTTG \\
clu-miR-9b-3p & AGTGGTTCTCAACAGTTCAACA \\
& ATGACCTATGAATTGACAGCCA \\
\hline
\end{tabular}

\section{Results}

\subsection{Total RNA Extraction, Library Preparation, and Small RNA Sequencing}

Total RNA extracted from 32 samples (brain, muscle, gill, liver, spleen, and head kidney from five adult fish and two samples each from larvae and embryos) showed concentrations ranging from 100 to $3250 \mathrm{ng} / \mu \mathrm{L}$ (Table S1) and intact 28S and 18S bands in $1 \%$ agarose gel indicated that they were of high quality. All these samples qualified for further analysis by HTS and qPCR. Small RNA libraries were successfully generated for 
16 samples (twelve tissue samples from two adult fish and two samples from each early developmental stage). The HTS resulted in a total of 147,972,041 raw reads, ranging from 6.6 to 13.3 million reads per sample. After adapter trimming, there were a total of 86,054,423 reads ranging from 4.5 to 6.9 million reads per sample (Table S2). All raw HTS results were submitted to NCBI with BioProject accession number PRJNA679415. The individual SRA accession numbers are given in Table S2.

\subsection{Characterization of Lumpfish miRNA}

The processed reads from each sample were analyzed with miRDeep2 software for miRNA gene discovery (Figure 1). Subsequent BLAST homology searches of all putative miRNA precursor sequences against miRbase revealed a total of 391 miRNA genes from 104 different families that were lumpfish orthologs to evolutionarily conserved miRNAs. They were subsequently annotated as the lumpfish orthologs of these miRNAs. The miRDeep2 analysis also revealed $5 p$ or $3 p$ arm domination (most abundant mature miRNA from a given precursor) and the genome location of each miRNA gene. An overview of all precursor sequences along with their corresponding $5 p$ and $3 p$ mature sequences is given for all evolutionarily conserved miRNA genes in Table S3.

A total of 98 precursors identified by miRDeep2 did not show significant matches in the homology analyses against miRBase. These were considered as putative novel miRNA precursor sequences. They were further analyzed by blastn searches against RNA databases in GenBank, small RNA databases Rfam, functional RNA database fRNAdb, and lumpfish genome sequence (GenBank Accession: PRJNA625538). Sequences that had a significant hit against these databases were discarded from the analysis, as described in the methods section. Following this filtering process, eight precursor and corresponding mature sequences showed characteristics expected from true miRNAs. These eight miRNA precursor sequences are likely to represent novel lumpfish miRNAs, and all these novel miRNA genes along with their corresponding $5 p$ and $3 p$ mature sequences, the observed arm dominance of mature sequences, and the genome location of each miRNA gene are given in the last part of Table S3. Finally, the mature miRNAs were aligned using Sequencher software to identify all unique mature miRNAs (many mature miRNAs from the same families were identical). There were 443 unique mature miRNAs. These unique miRNAs representing the lumpfish miRNAome are given in Supplementary File S4.

\subsection{Abundance of miRNAs within Organs and Developmental Stages}

We determined the diversity of miRNAs within the lumpfish tissues/organs and developmental stages based on the normalized read counts. The normalized read counts for all samples are shown in Table S5, while the average normalized read counts for each tissue/organ or developmental stage are shown in Table S6.

Our results show the presence of 340 unique mature miRNAs in the lumpfish brain, 328 in muscle, 289 in gill, 288 in the liver, 268 in the spleen, 289 in the head kidney, 328 in embryos, and 327 in larvae (Figure 2). Two hundred forty-one mature miRNAs were expressed in all six organs of adult lumpfish, 324 mature miRNAs were expressed commonly in embryos and larvae, and 223 mature miRNAs were expressed across all three developmental stages. All the miRNAs expressed in the early life stages, such as embryos and larvae, were also expressed in at least one organ of adult fish. The exceptions were clu-miR-19a-2-5p, which was only expressed in embryos, and clu-miR-137-1-5p, only in larvae. 


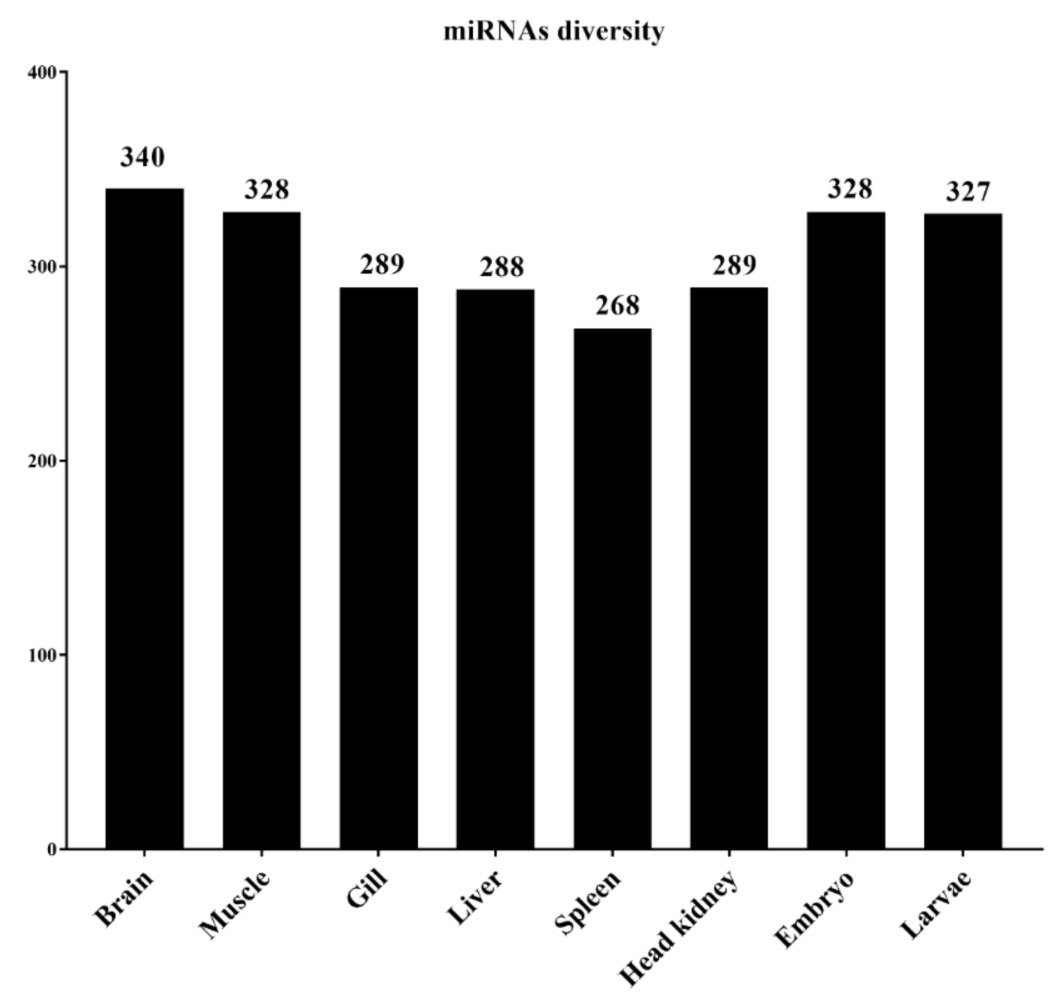

Figure 2. miRNA diversity in lumpfish tissue/organs and early developmental stages.

The abundance of most common mature miRNAs within each organ and developmental stage is shown in Figures 3 and 4, respectively. These figures show the distribution of the top 20 enriched mature miRNAs within each of the six organs and in the two early developmental stages. The abundances for all miRNAs within each of the organs and early developmental stages are shown in Table S6. Five of the top 20 enriched mature miRNAs, clu-miR-21a-5p, clu-miR-22ab-3p, clu-miR-26-1-5p, clu-miR-100-2-5p, and clulet-7g-5p were highly abundant within all organ and early developmental stages. While the five mature miRNAs clu-miR-146a-5p, clu-let-7a-3-5p, clu-miR-126-3p, clu-let-7e-5p, and clu-miR-143-3p were highly abundant miRNAs within all six organs of adult lumpfish, but not among the highly expressed miRNAs within lumpfish embryos and larvae (Figures 3 and 4). Additionally, several miRNAs were highly abundant within one of the tissue/organs from adult fish compared to others. For example, Clu-miR-122-1-5p, clu-miR-192a-5p, clu-miR-152ab-3p, and one novel miRNA (clu-miR-nov-5-5p) were also among the top 20 most abundant miRNAs in the liver, but with much lower abundance when comparing expression of miRNAs within other organs. Likewise, clu-miR-1-1-3p, clumiR-206-3p, and clu-miR-133ab-3p were abundant only in muscle, clu-miR-451a-5p only in spleen, clu-miR-142-2-3p only in head kidney, and clu-miR-9-2-5p and clu-miR-7-3-5p only in brain (Figure 3, Table S6). Two miRNAs, clu-miR-217b-5p and clu-miR-181b-3-5p, were common in the two early developmental stages while having relatively low expression within adult organs. In addition, there were some miRNAs common in one organ and early developmental stage. These were clu-miR-9-2-5p and clu-miR-7-3-5p (brain and early developmental stages), clu-miR-1-1-3p and clu-miR-206-3p (brain and early developmental stages) and clu-miR-192a-5p (liver and early developmental stages). 

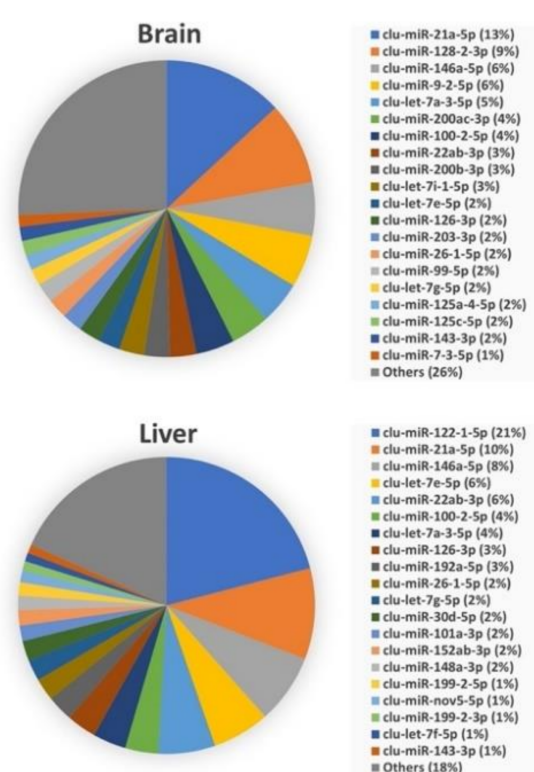
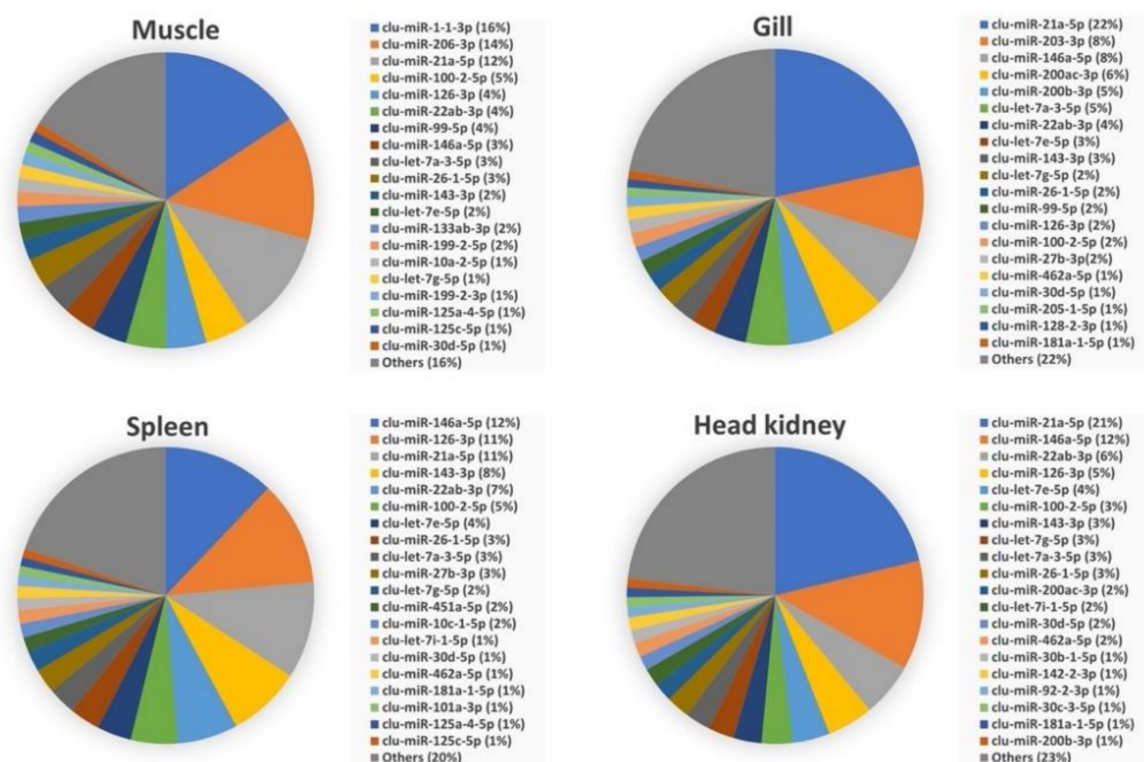

Figure 3. Twenty most abundant miRNAs in lumpfish brain, muscle, gill, liver, spleen, and head kidney.
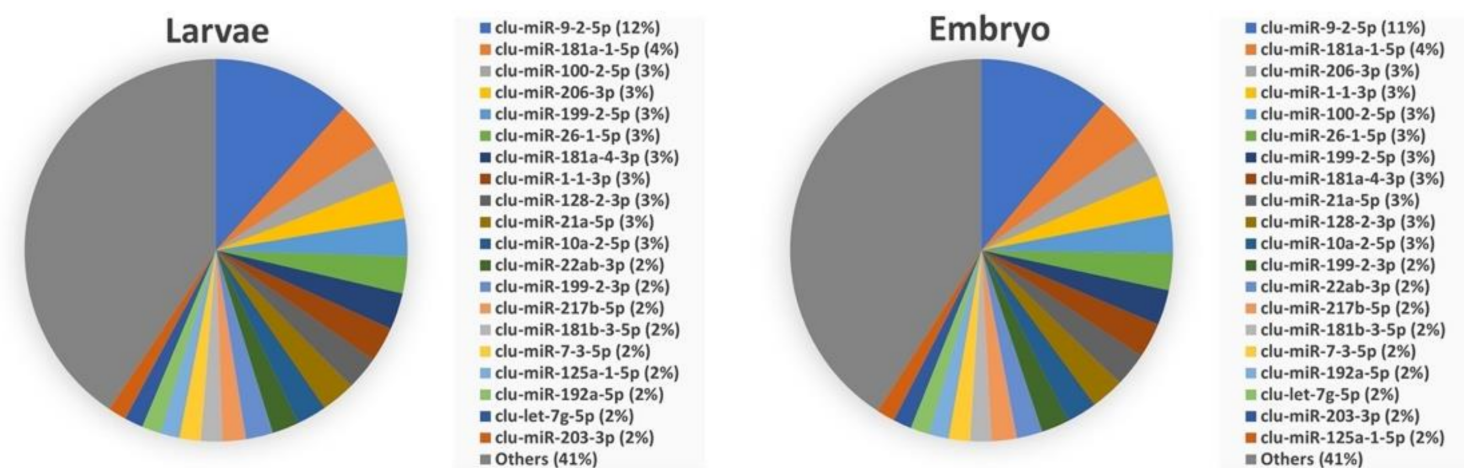

Figure 4. Twenty most abundant miRNAs in lumpfish embryos and larvae.

3.4. Comparison of Mature miRNA Expression between Organs and Early Developmental Stages

To further explore whether some miRNAs (any of the miRNAs, not only top common ones) were differentially expressed between adult organs or early developmental stages, we carried out expression analysis of the HTS data and additional RT-qPCR of selected miRNAs. DESeq2 analysis of the HTS data was conducted by comparing one organ or early developmental stage $(n=2)$ to all other samples $(n=14)$. The results (Table S7) suggested that several miRNAs have higher or lower expression in one organ or early developmental stages compared to all other samples. The suggested miRNAs with an increased expression $\left(\log _{2}\right.$ fold change $>3.0$ ) in a particular organ or early developmental stage compared to expression in all others are given in Tables 2 and 3, respectively. The numbers of such miRNAs were 9 in the brain, 5 in muscle, 8 in gill, 15 in the liver, 3 in the spleen, 13 in embryos, and 22 in larvae. However, our DESeq2 analysis did not suggest any enrichment of miRNAs in the lumpfish head kidney. 
Table 2. Mature miRNAs suggested as highly expressed in one organ compared to others.

\begin{tabular}{|c|c|c|}
\hline Organ $^{1}$ & miRNAs $^{2}$ & $\log _{2} \mathrm{FC}^{3}$ \\
\hline Brain & clu-miR-31-3p & 6.14 \\
\hline Brain & clu-miR-153c-3p & 5.96 \\
\hline Brain & clu-miR-153a-3p & 5.33 \\
\hline Brain & clu-miR-1788-5p & 4.91 \\
\hline Brain & clu-miR-212b-1-5p & 4.10 \\
\hline Brain & clu-miR-212b-1-3p & 3.14 \\
\hline Brain & clu-miR-128-2-3p & 3.49 \\
\hline Brain & clu-miR-338-1-3p & 3.40 \\
\hline Brain & clu-miR-132-1-5p & 3.08 \\
\hline Muscle & clu-miR-133b-3p & 6.08 \\
\hline Muscle & clu-miR-133ab-3p & 5.45 \\
\hline Muscle & clu-miR-1-1-3p & 5.23 \\
\hline Muscle & clu-miR-1-3-5p & 3.56 \\
\hline Gill & clu-miR-31-5p & 6.91 \\
\hline Gill & clu-miR-1788-3p & 6.21 \\
\hline Gill & clu-miR-203-3p & 5.13 \\
\hline Gill & clu-miR-203a-5p & 4.61 \\
\hline Gill & clu-miR-375-1-3p & 4.82 \\
\hline Gill & clu-miR-205-1-3p & 4.16 \\
\hline Gill & clu-miR-200b-3p & 3.8 \\
\hline Gill & clu-miR-200b-5p & 3.36 \\
\hline Liver & clu-miR-122-1-5p & 8.23 \\
\hline Liver & clu-miR-122-1-3p & 7.65 \\
\hline Liver & clu-miR-nov3-3p & 6.78 \\
\hline Liver & clu-miR-nov3-5p & 4.68 \\
\hline Liver & clu-miR-nov1-5p & 5.58 \\
\hline Liver & clu-miR-101b-3p & 4.83 \\
\hline Liver & clu-miR-101b-5p & 4.41 \\
\hline Liver & clu-miR-722-3p & 4.71 \\
\hline Liver & clu-miR-722-5p & 4.38 \\
\hline Liver & clu-miR-92b-3p & 4.04 \\
\hline Liver & clu-miR-92b-5p & 3.91 \\
\hline Liver & clu-miR-192a-5p & 3.75 \\
\hline Liver & clu-miR-94a-5p & 3.43 \\
\hline Liver & clu-miR-152ab-3p & 3.37 \\
\hline Liver & clu-miR-nov5-5p & 3.36 \\
\hline Spleen & clu-miR-2187b-5p & 5.10 \\
\hline Spleen & clu-miR-2187b-3p & 3.47 \\
\hline Spleen & clu-miR-460-5p & 3.27 \\
\hline
\end{tabular}

${ }^{1}$ Organ samples were obtained from adult lumpfish. ${ }^{2}$ The names are in a few cases with different lettered/numbered suffixes than in miRBase as several mature family members are identical. The miRNAs in the table are grouped in families, and the family member with the highest FC is used to list families in descending order. ${ }^{3} \log _{2}$-transformed fold-change (FC) as determined by DESeq2 analysis.

RT-qPCR was applied to verify the findings from the DESeq2 analysis in a few selected miRNAs. The two conserved mature miRNAs clu-mir-25-3p and clu-mir-17-5p, shown as suitable reference genes in other teleosts [20,55], revealed stable expression across all samples in this study (mean Ct values were $22.8 \pm 0.9$ (SD), $22.4 \pm 1.1$ (SD), respectively) and were, consequently, used as reference genes in the RT-qPCR analysis. Eight miRNAs known to be highly expressed in certain organs $[19,20]$ were selected for RT-qPCR (Table 1). These selected miRNAs showed significantly increased expression levels in the expected tissue/organs (Figure 5) that align with the literature $[19,20]$. For instance, clu-miR-135c-5p and clu-miR-9b-3p expression was significantly higher in brain, clu-miR-205b-5b, clu-miR203a-3p, and clu-miR-203b expression was significantly higher in gill, clu-miR-133-3p expression was significantly higher in muscle, and clu-miR-122-5p and clu-miR-192a-5p expression was significantly higher in liver compared with other tissue/organs. These qPCR results agreed with the DESeq2 results for six organ samples, while the increases 
observed for clu-miR-135c-5p and clu-miR-9b-3p in the brain were similar in the DESeq2 analysis but not significant. However, we utilized four or five biological replicates for the RT-qPCR analysis, whereas two were used in the DESeq2 analysis. Additionally, the significance levels were adjusted according to a large number of tests in the DESeq2 analysis. This could explain why the increases did not reach the significant thresholds in the DESeq2 analysis for these two miRNAs.

Table 3. Mature miRNAs suggested as highly expressed in embryos or larvae.

\begin{tabular}{|c|c|c|}
\hline Embryos/Larvae ${ }^{1}$ & $\operatorname{miRNAs}^{2}$ & $\log _{2} \mathrm{FC}^{3}$ \\
\hline Embryos & clu-miR-430b-5-5p & 5.61 \\
\hline Embryos & clu-miR-430b-4-3p & 4.51 \\
\hline Embryos & clu-miR-430b-1-3p & 4.37 \\
\hline Embryos & clu-miR-190b-5p & 5.45 \\
\hline Embryos & clu-miR-726-5p & 4.91 \\
\hline Embryos & clu-miR-184ab-2-3p & 4.77 \\
\hline Embryos & clu-miR-184ab-3p & 4.77 \\
\hline Embryos & clu-miR-301b-5p & 4.73 \\
\hline Embryos & clu-miR-301b-1-5p & 4.40 \\
\hline Embryos & clu-miR-124-1-5p & 4.40 \\
\hline Embryos & clu-miR-217b-5p & 4.23 \\
\hline Embryos & clu-miR-217a-5p & 4.13 \\
\hline Embryos & clu-miR-216a-1-5p & 4.20 \\
\hline Larvae & clu-miR-124-1-5p & 4.41 \\
\hline Larvae & clu-miR-130-1-5p & 3.15 \\
\hline Larvae & clu-miR-130-6-5p & 3.62 \\
\hline Larvae & clu-miR-183-5p & 4.09 \\
\hline Larvae & clu-miR-184ab-2-3p & 4.71 \\
\hline Larvae & clu-miR-184ab-3p & 4.71 \\
\hline Larvae & clu-miR-190b-5p & 5.44 \\
\hline Larvae & clu-miR-194b-3p & 3.46 \\
\hline Larvae & clu-miR-196a-1-5p & 3.95 \\
\hline Larvae & clu-miR-216a-1-5p & 4.00 \\
\hline Larvae & clu-miR-217a-5p & 4.11 \\
\hline Larvae & clu-miR-217b-5p & 4.11 \\
\hline Larvae & clu-miR-301b-1-5p & 4.38 \\
\hline Larvae & clu-miR-301b-3p & 3.44 \\
\hline Larvae & clu-miR-301b-5p & 4.70 \\
\hline Larvae & clu-miR-430a-12-3p & 3.97 \\
\hline Larvae & clu-miR-430a-3-3p & 3.97 \\
\hline Larvae & clu-miR-430b-1-3p & 4.28 \\
\hline Larvae & clu-miR-430b-4-3p & 4.40 \\
\hline Larvae & clu-miR-430b-5-5p & 5.41 \\
\hline Larvae & clu-miR-459-3p & 4.01 \\
\hline Larvae & clu-miR-726-5p & 4.64 \\
\hline
\end{tabular}

${ }^{1}$ Lumpfish embryos were obtained at 300 degree days, and lumpfish larvae were obtained after one-week posthatch. ${ }^{2}$ The names are in a few cases with different lettered/numbered suffixes than in miRBase as several mature family members are identical. The miRNAs in the table are grouped in families, and the family member with the highest FC is used to list families in descending order. ${ }^{3} \log _{2}$-transformed fold-change (FC) as determined by DESeq2 analysis. 

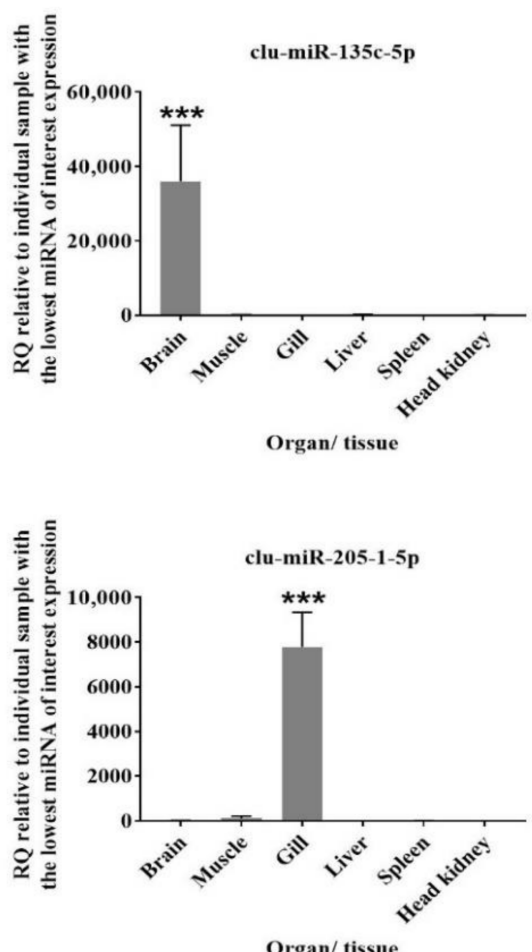

Organ/ tissue

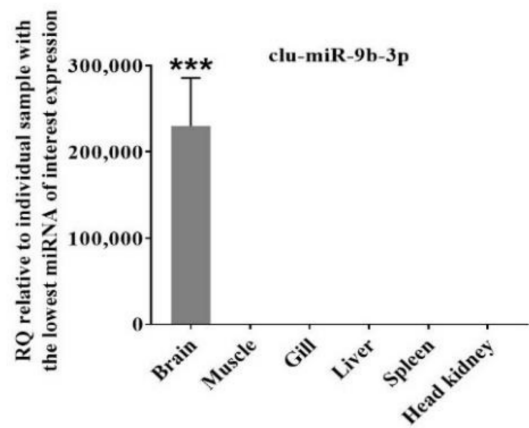

Organ/ tissue

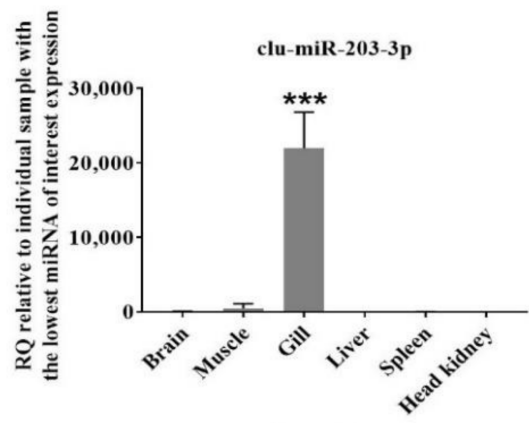

Organ/ tissue

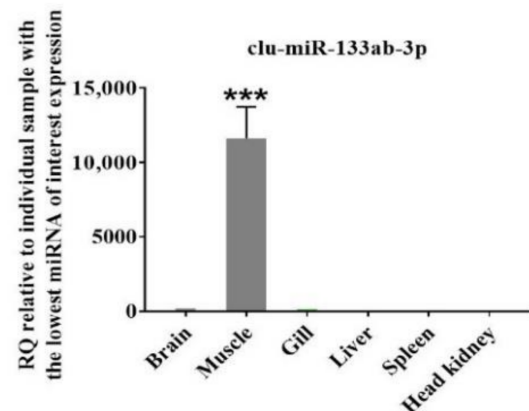

Organ/ tissue

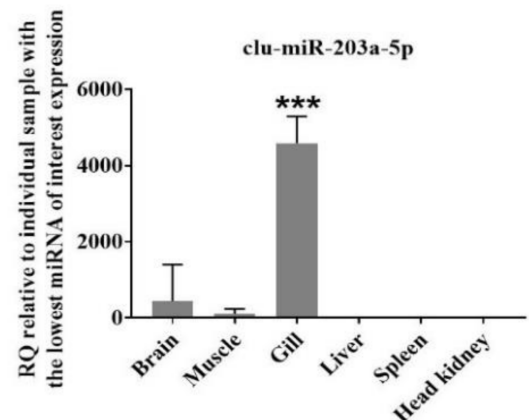

Organ/ tissue
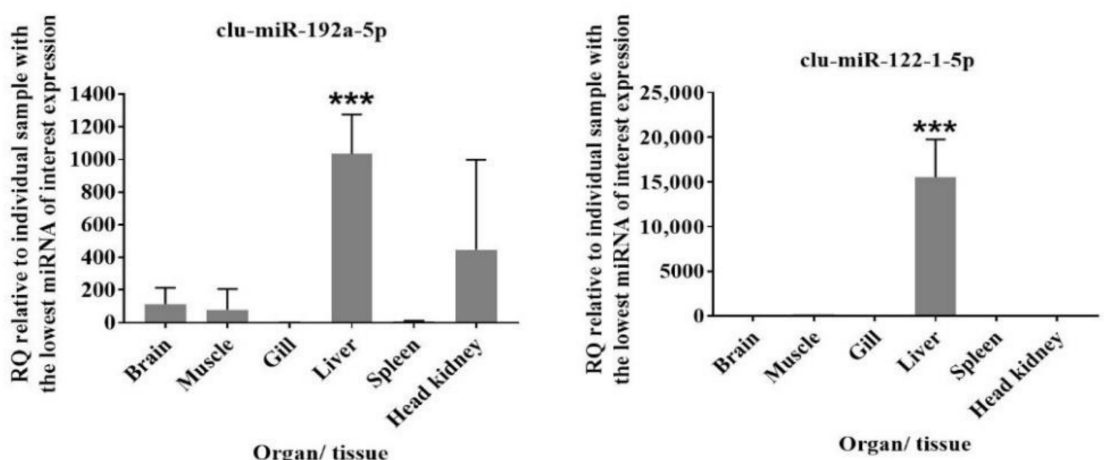

Figure 5. Verification of tissue-specific expression of conserved miRNAs. RT-qPCR results show the relative expression of eight miRNAs (clu-miR-135c-5p, clu-miR-9b-3p, clu-miR-133ab-3p, clu-miR-2051-5b, clu-miR-203-3p, clu-miR-203a-5p, clu-miR-192a-5p, clu-miR-122-1-5p ) across lumpfish organs (brain, muscle, gill, liver, spleen, and head kidney). Number of replicates for tissue samples were five $(n=5)$ except brain $(n=4)$ and muscle $(n=4)$. RQ: relative quantity normalized to clu-miR-25-3p and clu-miR-17-1-5p and calibrated to the individual sample with the lowest miRNA of interest expression. ${ }^{* * *}$ on the top of a particular sample indicates that the expression of the particular miRNA is significantly higher when compared to others by one-way ANOVA $(p<0.001)$.

\section{Discussion}

miRNAs play a significant role in embryonic development, determination of cell fate, and control of cell proliferation, differentiation, and death. Their dysregulation has a significant impact on critical cellular pathways and is linked to a variety of diseases $[11,13,16,48]$. A species-specific and well-characterized miRNAome generated from small RNA sequencing of different developmental stages is required to study miRNA expression by analysis of HTS data. Characterization of miRNAs in multiple organs and developmental stages in a new aquaculture species like lumpfish will also facilitate further studies to determine their role in development, whether they regulate organ developmental stage-specific functions, immune responses to infectious diseases, and disease progression. Therefore, this study 
was undertaken to define and characterize miRNAs expressed in the brain, muscle, gill, liver, spleen, and head kidney of adult lumpfish, as well as the two developmental stages, embryos and larvae. Together this resulted in a miRNAome consisting of 443 unique mature miRNAs that were used as lumpfish miRNA reference for analysis of HTS data and primer design (RT-qPCR analysis) of single miRNAs.

The expression of different miRNAs within an organ or developmental stage would reveal which ones were highly abundant and likely to have essential regulatory functions. Comparisons between adult organs and early developmental stages could further reveal the highly expressed ones in a few or single organs. We applied DESeq2 analysis to demonstrate that the miRNAome worked well as a reference in such HTS analysis. However, as there were two biological replicates of each adult organ (or early developmental stages) compared to all other HTS samples ( $n=14)$ in these analyses, we report them as suggestive expression differences. Ideally, there should be three or more biological replicates in each group compared in such analysis. However, we did choose a rather conservative $\log _{2} \mathrm{FC}$ ( 3 or more) to suggest them as differently expressed between organs (Table S7), and some of the miRNAs increased in particular organs were also supported in the additional RT-qPCR analysis (Figure 5).

Our analysis identified that 10 mature miRNAs were highly abundant and among the top 20 enriched miRNAs within all six organs (five were also among the top 20 enriched in the early developmental stages). These 10 mature miRNAs (clu-let-7a-3-5p, clu-let-7e5p, clu-let-7g-5p, clu-miR-21a-5p, clu-miR-22ab-3p, clu-miR-26-1-5p, clu-miR-100-2-5p, clu-miR-126-3p, clu-miR-143-3p, and clu-miR-146a-5p) are conserved miRNA families discovered in the majority of vertebrates in miRBase $[19,20,58]$. Their high expression within all adult organs could suggest that these miRNAs play a critical role in lumpfish cellular homeostasis. Still, as they are highly abundant in all adult organs, they are not likely to regulate organ-specific functions.

The brain receives information from sense organs that monitor conditions both within and around the fish. In the brain, the immune cells and the central nervous system interactions allow the immune system to fight against infection and enable the nervous system to regulate immune functioning $[59,60]$. Any change in these interaction pathways can cause many pathological conditions attributed to organ dysfunction $[59,60]$. However, miRNAs are critical brain development and function regulators, such as neuronal activity [11,61]. Our miRDeep2 analysis identified 340 conserved mature miRNAs in the lumpfish brain. Among highly enriched in the brain are clu-miR-9-2-5p and clu-miR-7-3-5p. These two miRNAs do not have similar high relative expression levels within any other adult organs but are similarly enriched in the two early developmental stages, indicating they could be important in developing neural tissue in lumpfish (Table S6). A similar enrichment pattern of miR-9-5p is seen in Atlantic salmon, cod, halibut, three-spined stickleback, and zebrafish brain $[19,20,22,28]$. Enrichment of miR-7 in the brain is also observed across vertebrates [62]. Several studies have shown that these two miRNAs are crucial for brain development in zebrafish and other vertebrates [63-65], and it is likely that clu-miR-9-2-5p and clu-miR7-3-5p may have similar functions in lumpfish. The DESeq2 analysis also suggested that clu-miR-128-2-3p, clu-miR-153c-3p, clu-miR-212b-1-5p, and clu-miR-338-1-3p were more than 10-times higher expressed in the brain than other organs (Table S7a). Similar findings were observed in Atlantic cod, three-spined stickleback, and zebrafish $[19,66]$. In higher vertebrates, miR-128 controls neural motor behaviours by regulating the expression of various ion channels [67]. The three other miRNAs have also all been reported as having important brain functions in higher vertebrates [68-70].

Fish muscles are the major edible parts worldwide, determining the nutritional and the market value. The teleost muscle is also an immunologically active organ, playing an important role against pathogens [71]. MicroRNAs are established modulators of muscle cell proliferation, differentiation, regeneration, and diseases [72]. Our miRDeep2 analysis identified 328 conserved mature miRNAs in lumpfish muscle. The muscle-specific top enriched miRNAs were clu-miR-1-1-3p and clu-miR-133ab-3p (present in other organs 
but much less abundant). Similar to our study, miR-133 and miR-1 were enriched in zebrafish, Atlantic salmon, and cod, suggesting the maintenance of muscle-specific miRNAs expression and function [18-20,73]. For example, miR-133 is one of the foremost studied and best-characterized miRNAs in vertebrates. It is required for proper skeletal and cardiac muscle development and function in mammals and fish [74,75]. On the other hand, miR-1 is a conserved miRNA in the muscle tissue that plays a crucial role in maintaining muscle integrity [76].

Because of direct exposure to the water, teleost gills are the main mucosal surfaces for the entrance of pathogens, which trigger an immune response [77]. miRNAs are important regulators of immune response to those infections in the gills of fish [20,78,79]. However, our DESEq2 analysis was on apparently healthy organs and suggested the enrichment of clu-miR-200 and clu-miR-203 family members and clu-miR-205-1-3p, clu-miR-375-1$3 p$, clu-miR-31-5p, and clu-miR-1788-3p in lumpfish gill. RT-qPCR results confirmed the enrichment of clu-miR-203-3p, clu-miR-203a-5p, and clu-miR-205-1-5p. Some of these miRNAs, such as miR-200, miR-205, and miR-375, were enriched in cod gill as well [20], while miR-200, miR-203, and miR-205 were enriched in gills of tilapia [80]. One of these miRNAs, miR-200, has been shown as important to gill function in cell studies of fish [81]. However, no study has been conducted to decipher the gill-associated role of the remaining five lumpfish miRNAs suggested as differentially expressed in teleost gill.

The liver is involved in various vital functions in controlling biochemical processes, including detoxification and metabolism [82]. miRNAs are essential for regulating liver development and functions, and alterations in intrahepatic miRNA networks have been associated with liver disease in humans [83]. They are also associated with hepatic lipid metabolism in Atlantic salmon [84]. Our miRDeep analysis identified 288 conserved mature miRNAs in the lumpfish liver (Table S6).

Four of the top 20 enriched miRNAs in liver-clu-miR-122-1-5p, clu-miR-152ab-3p, clu-miR-192a-5p and clu-miR-nov5-5p-did not show similar enrichment in any other adult organs (Figure 3). DESEq2 analysis also suggested these as having significantly increased expression in the liver, and this was confirmed by RT-qPCR for clu-miR-122-1-5p and clu-miR-192a-5p (Figure 5). This finding is similar to other teleosts and mammals $[20,85,86]$. miR-122 is the most abundant miRNA in the liver of many species. In mammals, miR-122 is studied extensively and is known to be involved in lipid metabolism [85]. Furthermore, miR-192 is involved in cell growth, lipid synthesis, and apoptosis [87] and having such roles also aligns with this miRNA being among the top 20 miRNAs expressed in the early developmental stage samples (Figure 4). Dysregulation of miR-152 is associated with liver disease in higher vertebrates indicating they are important hepatic miRNAs [84,88]. Based on the high conservation of these miRNAs among vertebrates (miRBase 22.1) [58] and with a similar enrichment pattern observed in lumpfish, we could assume they also play a similar liver-specific role in lumpfish.

As the body's primary blood filter, the spleen plays a major role in detecting cell damage during infection [89]. The spleen is the home of different types of immune cells that trigger different immune responses [89-91]. Splenic miRNAs have been identified to modulate immune responses during diseases in humans, mice, chickens, dogs, and fishes [92-99]. Our miRDeep analysis identified 268 conserved mature miRNAs in the lumpfish spleen. One mature miRNA, clu-miR-451a-5p, was only among the top 20 enriched miRNAs in the spleen, and this particular miRNA has been shown to regulate erythroid maturation in zebrafish [100]. Furthermore, our DESeq2 analysis suggested the enrichment of clu-miR2187b-5p and clu-miR-460-5p in the lumpfish spleen. These two miRNAs are also enriched in Atlantic salmon and cod spleen $[19,20]$, but their particular function in the spleen has not yet been investigated.

The anteriormost part of the kidney in the teleost is referred to as the head kidney. It is predominantly a lymphoid compartment. The head kidney is an essential hematopoietic organ and serves as a secondary lymphoid organ, a lymph node analog, vital in inducing and elaborating immune responses [90,91]. Assessing changes in the expression of miRNAs 
in the head kidney could provide more comprehensive insight into the immune response to infection. Our miRDeep2 analysis identified 289 conserved mature miRNAs in the lumpfish head kidney. Our DESeq2 analysis did not suggest any enrichment of miRNA in the head kidney.

The embryos and larvae samples did reveal several miRNAs suggested as early developmental stage enriched. Notably, the miR-430 family was suggested as enriched by the DESeq2 analysis. These are known as highly expressed in early development, and among suggested functions is maternal RNA clearance during early embryogenesis in zebrafish [101,102]. Another miRNA that was highly enriched and expressed only in the early developmental stages was clu-miR-217b-5p. This miRNA, as well as mature miRNAs from miR-124, miR-184, and miR-216 families that were also enriched in the lumpfish early developmental stages, have all been shown as important in zebrafish development [73].

\section{Conclusions}

In conclusion, this study represents the first characterization of a lumpfish miRNA transcriptome produced by independent analysis of small RNA sequences from several adult organs and early developmental stages. We identified 391 conserved and eight novel miRNA precursor sequences, which account for 443 unique mature miRNAs. Our results demonstrate that most of the lumpfish miRNAs are highly conserved with highly similar precursor sequences to those observed in other teleosts. Many miRNAs also appear to have similar tissue-specific expression patterns as in other vertebrates. Thus the miRNAs profile of lumpfish suggested a similar organ-specific expression pattern as other vertebrates. It is possible that these conserved miRNAs are regulating essential and conserved genes in vertebrates. Furthermore, the identification and characterization of lumpfish-specific novel miRNAs repertoire in this study will be crucial for further functional studies of the novel miRNAs in this species.

Supplementary Materials: The following are available online at https:/ / www.mdpi.com/article / 10.3390/biology11010130/s1, Table S1: Concentration and quality of RNA samples, Table S2: Descriptive data from small RNA sequenced samples, Table S3: All evolutionarily conserved and novel lumpfish miRNA genes discovered in different organs and developmental stages, File S4: Unique mature miRNAs, Table S5, Normalized read counts of individual mature miRNAs from sequencing data in each sample sequenced, Table S6: Relative distribution of miRNAs within organs and within developmental stages, Table S7: Mature miRNAs suggested as differentially expressed by DESeq2 analysis, Table S8: miRNAs analyzed by qPCR.

Author Contributions: Conceptualization, M.L.R., J.S., R.A.; formal analysis, S.C., N.T.W. and T.V.; data curation, N.T.W. and S.C.; writing-original draft, S.C., R.A., J.S.; writing-review \& editing S.C., R.A., M.L.R., D.B., J.S.; investigation, S.C.; project administration, J.S., R.A. and D.B. supervision, J.S. and R.A. All authors have read and agreed to the published version of the manuscript.

Funding: This research was funded by Norwegian Research Council grant 280839/E40 to R.A, Canada First-Ocean Frontier Institute (Module J), Atlantic Fisheries Funds, Genome Atlantic RP3 fund, Cooke Aquaculture division Cold Ocean Salmon-Newfoundland, Atlantic Canada Oportunities Agency (ACOA) and NSERC-Discovery grant (RGPIN-2018-05942) to J.S.

Institutional Review Board Statement: The fish dissection and tissue sample collection were performed following the Canadian Council on Animal Care guidelines and approved by Memorial University of Newfoundland's Institutional Animal Care Committee under protocols \#18-1-JS and \#18-03-JS.

Informed Consent Statement: Not applicable.

Data Availability Statement: All raw HTS results were submitted to NCBI with bio project accession number PRJNA679415. The individual SRA accession numbers are given in Table S2. 


\begin{abstract}
Acknowledgments: We thank Sanatander lab members (Memorial University of Newfoundland), JBARB personnel (Memorial University of Newfoundland), and Andreassen lab (Oslo Metropolitan University) for their logistical support. We are thankful for the sequencing services performed by the Genomics Core Facility Oslo (Oslo University Hospital, Norway).
\end{abstract}

Conflicts of Interest: The authors declare no conflict of interest.

\title{
References
}

1. Bhaskaran, M.; Mohan, M. MicroRNAs: History, biogenesis, and their evolving role in animal development and disease. Vet. Pathol. 2014, 51, 759-774. [CrossRef] [PubMed]

2. Michlewski, G.; Caceres, J.F. Post-transcriptional control of miRNA biogenesis. RNA 2019, 25, 1-16. [CrossRef] [PubMed]

3. Krol, J.; Loedige, I.; Filipowicz, W. The widespread regulation of microRNA biogenesis, function and decay. Nat. Rev. Genet. 2010, 11,597-610. [CrossRef]

4. Saliminejad, K.; Khorram Khorshid, H.R.; Soleymani Fard, S.; Ghaffari, S.H. An overview of microRNAs: Biology, functions, therapeutics, and analysis methods. J. Cell. Physiol. 2019, 234, 5451-5465. [CrossRef]

5. Bronevetsky, Y.; Ansel, K.M. Regulation of miRNA biogenesis and turnover in the immune system. Immunol. Rev. 2013, 253, 304-316. [CrossRef]

6. Matsuyama, H.; Suzuki, H.I. Systems and Synthetic microRNA Biology: From Biogenesis to Disease Pathogenesis. Int. J. Mol. Sci. 2019, 21, 132. [CrossRef]

7. De Sousa, M.C.; Gjorgjieva, M.; Dolicka, D.; Sobolewski, C.; Foti, M. Deciphering miRNAs' Action through miRNA Editing. Int. J. Mol. Sci. 2019, 20, 6249. [CrossRef] [PubMed]

8. Ha, M.; Kim, V.N. Regulation of microRNA biogenesis. Nat. Rev. Mol. Cell Biol. 2014, 15, 509-524. [CrossRef]

9. Hammond, S.M. An overview of microRNAs. Adv. Drug Deliv. Rev. 2015, 87, 3-14. [CrossRef] [PubMed]

10. Ravi, V.; Venkatesh, B. Rapidly evolving fish genomes and teleost diversity. Curr. Opin. Genet. Dev. 2008, 18, 544-550. [CrossRef]

11. Bizuayehu, T.T.; Babiak, I. MicroRNA in Teleost Fish. Genome Biol. Evol. 2014, 6, 1911-1937. [CrossRef]

12. Xue, X.; Woldemariam, N.T.; Caballero-Solares, A.; Umasuthan, N.; Fast, M.D.; Taylor, R.G.; Rise, M.L.; Andreassen, R. Dietary Immunostimulant CpG Modulates MicroRNA Biomarkers Associated with Immune Responses in Atlantic Salmon (Salmo salar). Cells 2019, 8, 1592. [CrossRef] [PubMed]

13. Smith, N.C.; Christian, S.L.; Woldemariam, N.T.; Clow, K.A.; Rise, M.L.; Andreassen, R. Characterization of miRNAs in Cultured Atlantic Salmon Head Kidney Monocyte-Like and Macrophage-Like Cells. Int. J. Mol. Sci. 2020, 21, 3989. [CrossRef] [PubMed]

14. Woldemariam, N.T.; Agafonov, O.; Sindre, H.; Høyheim, B.; Houston, R.D.; Robledo, D.; Bron, J.E.; Andreassen, R. miRNAs Predicted to Regulate Host Anti-viral Gene Pathways in IPNV-Challenged Atlantic Salmon Fry Are Affected by Viral Load, and Associated with the Major IPN Resistance QTL Genotypes in Late Infection. Front. Immunol. 2020, 11, 2113. [CrossRef] [PubMed]

15. Andreassen, R.; Woldemariam, N.T.; Egeland, I.O.; Agafonov, O.; Sindre, H.; Hoyheim, B. Identification of differentially expressed Atlantic salmon miRNAs responding to salmonid alphavirus (SAV) infection. BMC Genom. 2017, 18, 349. [CrossRef]

16. Andreassen, R.; Høyheim, B. miRNAs associated with immune response in teleost fish. Dev. Comp. Immunol. 2017, 75, 77-85. [CrossRef] [PubMed]

17. Eslamloo, K.; Inkpen, S.M.; Rise, M.L.; Andreassen, R. Discovery of microRNAs associated with the antiviral immune response of Atlantic cod macrophages. Mol. Immunol. 2018, 93, 152-161. [CrossRef]

18. Andreassen, R.; Worren, M.M.; Høyheim, B. Discovery and characterization of miRNA genes in atlantic salmon (Salmo salar) by use of a deep sequencing approach. BMC Genom. 2013, 14, 482. [CrossRef] [PubMed]

19. Woldemariam, N.T.; Agafonov, O.; Høyheim, B.; Houston, R.D.; Taggart, J.B.; Andreassen, R. Expanding the miRNA Repertoire in Atlantic Salmon; Discovery of IsomiRs and miRNAs Highly Expressed in Different Tissues and Developmental Stages. Cells 2019, 8, 42. [CrossRef]

20. Andreassen, R.; Rangnes, F.; Sivertsen, M.; Chiang, M.; Tran, M.; Worren, M.M. Discovery of miRNAs and Their Corresponding miRNA Genes in Atlantic Cod (Gadus morhua): Use of Stable miRNAs as Reference Genes Reveals Subgroups of miRNAs That Are Highly Expressed in Particular Organs. PLoS ONE 2016, 11, e0153324. [CrossRef]

21. Ma, H.; Hostuttler, M.; Wei, H.; Rexroad, C.E., 3rd; Yao, J. Characterization of the rainbow trout egg microRNA transcriptome. PLOS ONE 2012, 7, e39649.

22. Bizuayehu, T.T.; Fernandes, J.M.O.; Johansen, S.D.; Babiak, I. Characterization of Novel Precursor miRNAs Using Next Generation Sequencing and Prediction of miRNA Targets in Atlantic Halibut. PLoS ONE 2013, 8, e61378. [CrossRef]

23. Xu, Z.; Chen, J.; Li, X.; Ge, J.; Pan, J.; Xu, X. Identification and Characterization of MicroRNAs in Channel Catfish (Ictalurus punctatus) by Using Solexa Sequencing Technology. PLoS ONE 2013, 8, e54174. [CrossRef] [PubMed]

24. Fu, Y.; Shi, Z.; Wu, M.; Zhang, J.; Jia, L.; Chen, X. Identification and Differential Expression of MicroRNAs during Metamorphosis of the Japanese Flounder (Paralichthys olivaceus). PLoS ONE 2011, 6, e22957. [CrossRef]

25. Xia, J.H.; He, X.P.; Bai, Z.Y.; Yue, G.H. Identification and Characterization of 63 MicroRNAs in the Asian Seabass Lates calcarifer. PLoS ONE 2011, 6, e17537. [CrossRef] [PubMed]

26. Robledo, D.; Martin, A.P.; Álvarez-Dios, J.A.; Bouza, C.; Pardo, B.G.; Martínez, P. First characterization and validation of turbot microRNAs. Aquaculture 2017, 472, 76-83. [CrossRef] 
27. Chen, P.Y.; Manninga, H.; Slanchev, K.; Chien, M.; Russo, J.J.; Ju, J.; Sheridan, R.; John, B.; Marks, D.S.; Gaidatzis, D.; et al. The developmental miRNA profiles of zebrafish as determined by small RNA cloning. Genes Dev. 2005, 19, 1288-1293. [CrossRef]

28. Desvignes, T.; Batzel, P.; Sydes, J.; Eames, B.F.; Postlethwait, J.H. miRNA analysis with Prost! reveals evolutionary conservation of organ-enriched expression and post-transcriptional modifications in three-spined stickleback and zebrafish. Sci. Rep. 2019, 9, 3913. [CrossRef]

29. DFO. Aquaculture in Atlantic Canada-Atlantic Salmon. 2021. Available online: https://www.canada.ca/en/atlantic-canadaopportunities/services / factsheetsandbrochures35.html (accessed on 21 January 2021).

30. DFO. Evaluation of Bacterial Kidney Disease (BKD) Impacts on the Canadian Salmon Aquaculture Industry Final Report; Fisheries and Oceans Canada (DFO): Ottawa, ON, Canada, 2010; Available online: https://www.cahs-bc.ca/wp-content/uploads/2019/03/ BKDWhitePaper_FinalApr2010_WithAppendices.pdf (accessed on 21 January 2021).

31. Akazawa, N.; Alvial, A.; Blanc, P.P.; Burgos, J.; Chamberlain, G.; Forster, J.; Hoang, T.; Ibarra, R.; Khoa, L.; Kibenge, F.; et al Reducing Disease Risk in Aquaculture - World Bank Report Number 88257-GLB; World Bank: Washington, DC, USA, 2014.

32. Brooker, A.J.; Papadopoulou, A.; Gutierrez, C.; Rey, S.; Davie, A.; Migaud, H. Sustainable production and use of cleaner fish for the biological control of sea lice: Recent advances and current challenges. Vet. Rec. 2018, 183, 383. [CrossRef]

33. Lam, C.T.; Rosanowski, S.M.; Walker, M.; St-Hilaire, S. Sea lice exposure to non-lethal levels of emamectin benzoate after treatments: A potential risk factor for drug resistance. Sci. Rep. 2020, 10, 932-938. [CrossRef]

34. Karbowski, C.; Finstad, B.; Karbowski, N.; Hedger, R. Sea lice in Iceland: Assessing the status and current implications for aquaculture and wild salmonids. Aquac. Environ. Interact. 2019, 11, 149-160. [CrossRef]

35. Aaen, S.M.; Helgesen, K.O.; Bakke, M.J.; Kaur, K.; Horsberg, T.E. Drug resistance in sea lice: A threat to salmonid aquaculture Trends Parasitol. 2015, 31, 72-81. [CrossRef] [PubMed]

36. Abolofia, J.; Asche, F.; Wilen, J.E. The Cost of Lice: Quantifying the Impacts of Parasitic Sea Lice on Farmed Salmon. Mar. Resour. Econ. 2017, 32, 329-349. [CrossRef]

37. Overton, K.; Dempster, T.; Oppedal, F.; Kristiansen, T.S.; Gismervik, K.; Stien, L.H. Salmon lice treatments and salmon mortality in Norwegian aquaculture: A review. Rev. Aquac. 2019, 11, 1398-1417. [CrossRef]

38. Barker, S.E.; Bricknell, I.R.; Covello, J.; Purcell, S.; Fast, M.D.; Wolters, W.; Bouchard, D.A. Sea lice, Lepeophtheirus salmonis (Krøyer 1837), infected Atlantic salmon (Salmo salar L.) are more susceptible to infectious salmon anemia virus. PLoS ONE 2019, 14, e0209178. [CrossRef]

39. Torrissen, O.; Jones, S.; Asche, F.; Guttormsen, A.; Skilbrei, O.T.; Nilsen, F.; Horsberg, T.E.; Jackson, D. Salmon lice-Impact on wild salmonids and salmon aquaculture. J. Fish Dis. 2013, 36, 171-194. [CrossRef]

40. Costello, M.J. The global economic cost of sea lice to the salmonid farming industry. J. Fish Dis. 2009, 32, 115-118. [CrossRef]

41. Barrett, L.T.; Overton, K.; Stien, L.H.; Oppedal, F.; Dempster, T. Effect of cleaner fish on sea lice in Norwegian salmon aquaculture: A national scale data analysis. Int. J. Parasitol. 2020, 50, 787-796. [CrossRef]

42. Imsland, A.K.D.; Hanssen, A.; Nytrø, A.V.; Reynolds, P.; Jonassen, T.M.; Hangstad, T.A.; Elvegård, T.A.; Urskog, T.C.; Mikalsen, B. It works! Lumpfish can significantly lower sea lice infestation in large-scale salmon farming. Biol. Open 2018, 7, bio036301. [CrossRef]

43. Vasquez, I.; Cao, T.; Chakraborty, S.; Gnanagobal, H.; O’Brien, N.; Monk, J.; Boyce, D.; Westcott, J.D.; Santander, J. Comparative Genomics Analysis of Vibrio anguillarum Isolated from Lumpfish (Cyclopterus lumpus) in Newfoundland Reveal Novel Chromosomal Organizations. Microorganisms 2020, 8, 1666. [CrossRef]

44. Chakraborty, S.; Cao, T.; Hossain, A.; Gnanagobal, H.; Vasquez, I.; Boyce, D.; Santander, J. Vibrogen-2 vaccine trial in lumpfish (Cyclopterus lumpus) against Vibrio anguillarum. J. Fish Dis. 2019, 42, 1057-1064. [CrossRef]

45. Dang, M.; Cao, T.; Vasquez, I.; Hossain, A.; Gnanagobal, H.; Kumar, S.; Hall, J.; Monk, J.; Boyce, D.; Westcott, J.; et al. Oral Immunization of Larvae and Juvenile of Lumpfish (Cyclopterus lumpus) against Vibrio anguillarum Does Not Influence Systemic Immunity. Vaccines 2021, 9, 819. [CrossRef]

46. Boyce, D.; Ang, K.P.; Prickett, R. Cunner and lumpfish as cleaner fish species in Canada. In Cleaner Fish Biology and Aquaculture Applications; Treasurer, J.W., Ed.; 5M Publishing: Sheffield, UK, 2018.

47. Shwe, A.; Østbye, T.-K.K.; Krasnov, A.; Ramberg, S.; Andreassen, R. Characterization of Differentially Expressed miRNAs and Their Predicted Target Transcripts during Smoltification and Adaptation to Seawater in Head Kidney of Atlantic Salmon. Genes 2020, 11, 1059. [CrossRef]

48. Knutsen, T.M.; Kirubakaran, G.T.; Mommens, M.; Moen, T. Lumpfish (Cyclopterus lumpus) Draft Genome Assembly; Figshare: Iasi, Romania, 2018.

49. Langmead, B.; Trapnell, C.; Pop, M.; Salzberg, S.L. Ultrafast and memory-efficient alignment of short DNA sequences to the human genome. Genome Biol. 2009, 10, R25. [CrossRef] [PubMed]

50. Friedlander, M.R.; Chen, W.; Adamidi, C.; Maaskola, J.; Einspanier, R.; Knespel, S.; Rajewsky, N. Discovering microRNAs from deep sequencing data using miRDeep. Nat. Biotechnol. 2008, 26, 407-415. [CrossRef]

51. Friedländer, M.R.; Mackowiak, S.D.; Li, N.; Chen, W.; Rajewsky, N. miRDeep2 accurately identifies known and hundreds of novel microRNA genes in seven animal clades. Nucleic Acids Res. 2012, 40, 37-52. [CrossRef]

52. Kozomara, A.; Griffiths-Jones, S. miRBase: Annotating high confidence microRNAs using deep sequencing data. Nucleic Acids Res. 2014, 42, D68-D73. [CrossRef] 
53. Griffiths-Jones, S.; Grocock, R.J.; Van Dongen, S.; Bateman, A.; Enright, A.J. miRBase: MicroRNA sequences, targets and gene nomenclature. Nucleic Acids Res. 2006, 34 (Supplement S1), D140-D144. [CrossRef] [PubMed]

54. Ambros, V.; Bartel, B.; Bartel, D.P.; Burge, C.B.; Carrington, J.C.; Chen, X.; Dreyfuss, G.; Eddy, S.R.; Griffiths-Jones, S.; Marshall, M.; et al. A uniform system for microRNA annotation. RNA 2003, 9, 277-279. [CrossRef] [PubMed]

55. Johansen, I.; Andreassen, R. Validation of miRNA genes suitable as reference genes in qPCR analyses of miRNA gene expression in Atlantic salmon (Salmo salar). BMC Res. Notes 2014, 7, 945. [CrossRef] [PubMed]

56. Ruijter, J.M.; Ramakers, C.; Hoogaars, W.M.H.; Karlen, Y.; Bakker, O.; van den Hoff, M.J.B.; Moorman, A.F.M. Amplification efficiency: Linking baseline and bias in the analysis of quantitative PCR data. Nucleic Acids Res. 2009, 37, e45. [CrossRef] [PubMed]

57. Schmittgen, T.D.; Livak, K.J. Analyzing real-time PCR data by the comparative C(T) method. Nat. Protoc. 2008, 3, 1101-1108. [CrossRef] [PubMed]

58. miRBase: The MicroRNA Database. Available online: http:/ / www.mirbase.org (accessed on 15 November 2012).

59. Dantzer, R.; Wollman, E.E. Relationships between the brain and the immune system. J. Société Biol. 2003, 197, 81-88. [CrossRef]

60. Dantzer, R. Neuroimmune Interactions: From the Brain to the Immune System and Vice Versa. Physiol. Rev. 2018, 98, 477-504. [CrossRef]

61. Brennan, G.; Henshall, D.C. MicroRNAs as regulators of brain function and targets for treatment of epilepsy. Nat. Rev. Neurol. 2020, 16, 506-519. [CrossRef]

62. Tessmar-Raible, K.; Raible, F.; Christodoulou, F.; Guy, K.; Rembold, M.; Hausen, H.; Arendt, D. Conserved Sensory-Neurosecretory Cell Types in Annelid and Fish Forebrain: Insights into Hypothalamus Evolution. Cell 2007, 129, 1389-1400. [CrossRef]

63. Giraldez, A.J.; Cinalli, R.M.; Glasner, M.E.; Enright, A.; Thomson, J.M.; Baskerville, S.; Hammond, S.M.; Bartel, D.P.; Schier, A.F. MicroRNAs Regulate Brain Morphogenesis in Zebrafish. Science 2005, 308, 833-838. [CrossRef]

64. Radhakrishnan, B.; Anand, A.A.P. Role of miRNA-9 in Brain Development. J. Exp. Neurosci. 2016, 10, JEN.S32843. [CrossRef]

65. Zhao, J.; Zhou, Y.; Guo, M.; Yue, D.; Chen, C.; Liang, G.; Xu, L. MicroRNA-7: Expression and function in brain physiological and pathological processes. Cell Biosci. 2020, 10, 1-12. [CrossRef]

66. Vaz, C.; Wee, C.W.; Lee, G.P.S.; Ingham, P.W.; Tanavde, V.; Mathavan, S. Deep sequencing of small RNA facilitates tissue and sex associated microRNA discovery in zebrafish. BMC Genom. 2015, 16, 950. [CrossRef]

67. Tan, C.L.; Plotkin, J.L.; Venø, M.T.; von Schimmelmann, M.; Feinberg, P.; Mann, S.; Handler, A.; Kjems, J.; Surmeier, D.J.; O'Carroll, D.; et al. MicroRNA-128 Governs Neuronal Excitability and Motor Behavior in Mice. Science 2013, 342, $1254-1258$. [CrossRef] [PubMed]

68. Tsuyama, J.; Bunt, J.; Richards, L.J.; Iwanari, H.; Mochizuki, Y.; Hamakubo, T.; Shimazaki, T.; Okano, H. MicroRNA-153 Regulates the Acquisition of Gliogenic Competence by Neural Stem Cells. Stem Cell Rep. 2015, 5, 365-377. [CrossRef]

69. Wanet, A.; Tacheny, A.; Arnould, T.; Renard, P. miR-212/132 expression and functions: Within and beyond the neuronal compartment. Nucleic Acids Res 2012, 40, 4742-4753. [CrossRef] [PubMed]

70. Howe, J.; Li, E.S.; Streeter, S.E.; Rahme, G.; Chipumuro, E.; Russo, G.B.; Litzky, J.F.; Hills, L.B.; Rodgers, K.; Skelton, P.; et al. MiR-338-3p regulates neuronal maturation and suppresses glioblastoma proliferation. PLoS ONE 2017, 12, e0177661. [CrossRef] [PubMed]

71. Valenzuela, C.A.; Zuloaga, R.; Poblete-Morales, M.; Vera-Tobar, T.; Mercado, L.; Avendaño-Herrera, R.; Valdés, J.A.; Molina, A. Fish skeletal muscle tissue is an important focus of immune reactions during pathogen infection. Dev. Comp. Immunol. 2017, 73, 1-9. [CrossRef] [PubMed]

72. Brzeszczyńska, J.; Brzeszczyński, F.; Hamilton, D.F.; McGregor, R.; Simpson, A.H.R.W. Role of microRNA in muscle regeneration and diseases related to muscle dysfunction in atrophy, cachexia, osteoporosis, and osteoarthritis. Bone Jt. Res. 2020, 9, $798-807$. [CrossRef]

73. Bhattacharya, M.; Sharma, A.R.; Sharma, G.; Patra, B.C.; Nam, J.-S.; Chakraborty, C.; Lee, S.-S. The crucial role and regulations of miRNAs in zebrafish development. Protoplasma 2017, 254, 17-31. [CrossRef]

74. Yu, H.; Lu, Y.; Li, Z.; Wang, Q. microRNA-133: Expression, Function and Therapeutic Potential in Muscle Diseases and Cancer. Curr. Drug Targets 2014, 15, 817-828. [CrossRef]

75. Zhang, R.; Li, R.; Lin, Y. Identification and characterization of microRNAs in the muscle of Schizothorax prenanti. Fish Physiol. Biochem. 2017, 121, 207-1064. [CrossRef]

76. Horak, M.; Novak, J.; Bienertova-Vasku, J. Muscle-specific microRNAs in skeletal muscle development. Dev. Biol. 2016, 410, 1-13. [CrossRef]

77. Yu, Y.; Wang, Q.; Huang, Z.; Ding, L.; Xu, Z. Immunoglobulins, Mucosal Immunity and Vaccination in Teleost Fish. Front. Immunol. 2020, 11, 567941. [CrossRef]

78. Zhang, Q.-L.; Dong, Z.-X.; Luo, Z.-W.; Jiao, Y.-J.; Guo, J.; Deng, X.-Y.; Wang, F.; Chen, J.-Y.; Lin, L.-B. MicroRNA profile of immune response in gills of zebrafish (Danio rerio) upon Staphylococcus aureus infection. Fish Shellfish. Immunol. 2019, 87, 307-314. [CrossRef] [PubMed]

79. Juanchich, A.; Bardou, P.; Rué, O.; Gabillard, J.-C.; Gaspin, C.; Bobe, J.; Guiguen, Y. Characterization of an extensive rainbow trout miRNA transcriptome by next generation sequencing. BMC Genom. 2016, 17, 164. [CrossRef]

80. Su, H.; Fan, J.; Ma, D.; Zhu, H. Identification and Characterization of Osmoregulation Related MicroRNAs in Gills of Hybrid Tilapia Under Three Types of Osmotic Stress. Front. Genet. 2021, 12, 361. [CrossRef] 
81. Ng, H.M.; Ho, J.C.H.; Nong, W.; Hui, J.H.L.; Lai, K.P.; Wong, C.K.C. Genome-wide analysis of MicroRNA-messenger RNA interactome in ex-vivo gill filaments, Anguilla japonica. BMC Genom. 2020, 21, 208. [CrossRef]

82. Sales, C.F.; Silva, R.F.; Amaral, M.G.C.; Domingos, F.F.T.; Ribeiro, R.I.M.A.; Thomé, R.G.; Santos, H.B. Comparative histology in the liver and spleen of three species of freshwater teleost. Neotrop. Ichthyol. 2017, 15. [CrossRef]

83. Dai, Z.; Yang, T.; Song, G. The roles of miRNAs in liver diseases. Non-Coding RNA Investig. 2019, 3, 25. [CrossRef]

84. Østbye, T.K.; Woldemariam, N.T.; Lundberg, C.E.; Berge, G.M.; Ruyter, B.; Andreassen, R. Modulation of hepatic miRNA expression in Atlantic salmon (Salmo salar) by family background and dietary fatty acid composition. J. Fish Biol. 2021, 98, 1172-1185. [CrossRef] [PubMed]

85. Lagos-Quintana, M.; Rauhut, R.; Yalcin, A.; Meyer, J.; Lendeckel, W.; Tuschl, T. Identification of Tissue-Specific MicroRNAs from Mouse. Curr. Biol. 2002, 12, 735-739. [CrossRef]

86. Trattner, S.; Vestergren, A.S. Tissue distribution of selected microRNA in Atlantic salmon. Eur. J. Lipid Sci. Technol. 2013, 115, 1348-1356. [CrossRef]

87. Liu, X.-L.; Cao, H.-X.; Wang, B.-C.; Xin, F.-Z.; Zhang, R.-N.; Zhou, D.; Yang, R.-X.; Zhao, Z.-H.; Pan, Q.; Fan, J.-G. miR-192-5p regulates lipid synthesis in non-alcoholic fatty liver disease through SCD-1. World J. Gastroenterol. 2017, 23, 8140-8151. [CrossRef]

88. Su, H.; Yang, J.-R.; Xu, T.; Huang, J.; Xu, L.; Yuan, Y.; Zhuang, S.-M. MicroRNA-101, Down-regulated in Hepatocellular Carcinoma, Promotes Apoptosis and Suppresses Tumorigenicity. Cancer Res. 2009, 69, 1135-1142. [CrossRef]

89. Bronte, V.; Pittet, M.J. The Spleen in Local and Systemic Regulation of Immunity. Immunity 2013, 39, 806-818. [CrossRef] [PubMed]

90. Kaattari, S.L.; Irwin, M.J. Salmonid spleen and anterior kidney harbor populations of lymphocytes with different B cell repertoires. Dev. Comp. Immunol. 1985, 9, 433-444. [CrossRef]

91. Press, C.; Evensen, Ø. The morphology of the immune system in teleost fishes. Fish Shellfish Immunol. 1999, 9, 309-318. [CrossRef]

92. Li, G.; Zhao, Y.; Wen, L.; Liu, Z.; Yan, F.; Gao, C. Identification and Characterization of MicroRNAs in the Spleen of Common Carp Immune Organ. J. Cell. Biochem. 2014, 115, 1768-1778. [CrossRef]

93. Cao, Y.; Wang, D.; Li, S.; Zhao, J.; Xu, L.; Liu, H.; Lu, T.; Mou, Z. A transcriptome analysis focusing on splenic immune-related mciroRNAs of rainbow trout upon Aeromonas salmonicida subsp. salmonicida infection. Fish Shellfish. Immunol. 2019, 91, 350-357. [CrossRef] [PubMed]

94. Zhou, Y.; Wang, Y.-Y.; Fu, H.-C.; Huang, H.-Z. MicroRNA expression and analysis of immune-related putative target genes in ISKNV-infected spleen of mandarin fish (Siniperca chuatsi). Aquaculture 2021, 547, 737450. [CrossRef]

95. Grimes, J.A.; Prasad, N.; Levy, S.; Cattley, R.; Lindley, S.; Boothe, H.W.; Henderson, R.A.; Smith, B.F. A comparison of microRNA expression profiles from splenic hemangiosarcoma, splenic nodular hyperplasia, and normal spleens of dogs. BMC Vet. Res. 2016, 12, 272. [CrossRef] [PubMed]

96. Li, Z.J.; Zhang, Y.P.; Li, Y.; Zheng, H.W.; Zheng, Y.S.; Liu, C.J. Distinct expression pattern of miRNAs in Marek's disease virus infected-chicken splenic tumors and non-tumorous spleen tissues. Res. Vet. Sci. 2014, 97, 156-161. [CrossRef] [PubMed]

97. He, J.-J.; Ma, J.; Wang, J.-L.; Xu, M.-J.; Zhu, X.-Q. Analysis of miRNA expression profiling in mouse spleen affected by acute Toxoplasma gondii infection. Infect. Genet. Evol. 2016, 37, 137-142. [CrossRef] [PubMed]

98. Arribas, A.J.; Gomez-Abad, C.; Sánchez-Beato, M.; Martinez, N.; DiLisio, L.; Casado, F.; Cruz, M.A.; Algara, P.; Piris, M.A.; Mollejo, M. Splenic marginal zone lymphoma: Comprehensive analysis of gene expression and miRNA profiling. Mod. Pathol. 2013, 26, 889-901. [CrossRef]

99. Huang, L.; Ma, J.; Sun, Y.; Lv, Y.; Lin, W.; Liu, M.; Tu, C.; Zhou, P.; Gu, W.; Su, S.; et al. Altered splenic miRNA expression profile in H1N1 swine influenza. Arch. Virol. 2015, 160, 979-985. [CrossRef] [PubMed]

100. Pase, L.; Layton, J.E.; Kloosterman, W.P.; Carradice, D.; Waterhouse, P.M.; Lieschke, G.J. miR-451 regulates zebrafish erythroid maturation in vivo via its target gata2. Blood 2009, 113, 1794-1804. [CrossRef]

101. Giraldez, A.J.; Mishima, Y.; Rihel, J.; Grocock, R.J.; Van Dongen, S.; Inoue, K.; Enright, A.J.; Schier, A.F. Zebrafish MiR-430 Promotes Deadenylation and Clearance of Maternal mRNAs. Science 2006, 312, 75-79. [CrossRef] [PubMed]

102. Takacs, C.M.; Giraldez, A.J. miR-430 regulates oriented cell division during neural tube development in zebrafish. Dev. Biol. 2016, 409, 442-450. [CrossRef] 